\title{
Exploring Asynchronous and Synchronous Tool use in Online Courses
}

\author{
Murat Oztok $^{\mathrm{a}}$, Daniel Zingaro ${ }^{\mathrm{a}}$, Clare Brett ${ }^{\mathrm{a}}$, Jim Hewitt ${ }^{\mathrm{a}}$ \\ ${ }^{a}$ Department of Curriculum, Teaching and Learning, Ontario Institute for Studies in \\ Education, University of Toronto
}

\begin{abstract}
While the independent contributions of synchronous and asynchronous interaction in online learning are clear, comparatively less is known about the pedagogical consequences of using both modes in the same environment. In this study, we examine relationships between students' use of asynchronous discussion forums and synchronous private messages (PM). We find that asynchronous notes contain more academic language and less social language, are more difficult to read, and are longer compared to PM. In addition, we find that the most active forum-posters are also the most active PM users, suggesting that PMing is not reducing their contribution to public discourse. Finally, we find that those who frequently PM are less likely to rapidly scan forum notes, and that they spend more time online than those who make less use of PM. We suggest that PM supports asynchronous discussions in the formation of a community of inquiry.
\end{abstract}

Keywords: computer-mediated communication

\section{Introduction}

Although research so far has clearly described the independent advantages and disadvantages of using synchronous or asynchronous tools in online learning environments, there are comparably few studies investigating the pedagogical outcomes when synchronous and asynchronous technologies

Email addresses: murat.oztok@utoronto.ca (Murat Oztok), daniel.zingaro@utoronto.ca (Daniel Zingaro), clare.brett@utoronto.ca (Clare Brett), jim.hewitt@utoronto.ca (Jim Hewitt) 
are converged. When such research does exist, it tends to focus on solving problems with the media itself, rather than its pedagogical role (Schwarz \& Asterhan, 2011). For example, Chen, Liu \& Wong (2007) provide a framework for evaluating synchronous and asynchronous media for students learning a second language. Their focus is squarely technical: the ability of synchronous media to support natural communication or automated instruction, for example. Beyond such important considerations, it is also necessary to investigate the pedagogical role of synchronous chat in the context of well-established asynchronous tools.

It is not enough to assume that the combination of synchronous and asynchronous media carries the benefits of each type of media in isolation. In particular, it is important to understand how individuals synchronous communication affects their asynchronous threaded discussions if we are to identify the pedagogical benefits and pitfalls of using a synchronous tool within an asynchronous online learning environment. The present study examines patterns of the use of messaging within an asynchronous online environment in order to better understand this relationship.

Our underlying perspective for this work is one of social constructivism. From such a standpoint, learning is shaped by context, conversation, and collaboration (Brown, Collins \& Duguid, 1989; Dewey, 1963; Vygotsky, 1978). Summarizing the importance of social constructivism for online learning practices, Swan (2005) suggests that "learning is essentially a social activity, [and] that meaning is constructed through communication, collaborative activity, and interactions with others. It highlights the role of social interactions in meaning making ... [and] knowledge construction" (p. 5). When social constructivism is employed as a theoretical framework, therefore, discussions become critical as they connect individuals in an online learning environment and motivate them to take an active role in knowledge construction and meaning-making processes (Fung, 2004; Henning, 2004; Stacey, 1999). For instance, Hill, Song \& West (2009) suggest that online environments should support threaded discussions, through which individuals "interact and observe the results of their interactions while responding to and engaging with others" (p. 89).

\section{Literature Review}

We highlight here, in turn, some of the often cited advantages and disadvantages of asynchronous and synchronous communication. Our purpose is 
to outline that each on its own confers significant advantages to the online learning experience.

\subsection{Asynchronous Communication}

Asynchronous communication is currently the dominant form of educational computer-mediated communication (CMC) (Johnson \& Aragon, 2003). It occurs in delayed time, and does not rely on simultaneous access for educational outcomes (Johnson, 2006). Such forums typically use thread structures to link together related notes, allowing students to follow multiple simultaneously-occurring discussions (Hewitt, 2005). Many authors highlight the benefits of threaded asynchronous CMC compared to synchronous CMC and face-to-face courses, including time-independent access, opportunities for heightened levels of peer interaction, avoidance of undesirable classroom behavior, and support for multiple learning styles (Morse, 2003). Asynchronous courses naturally support and embody core tenets of constructivist-based education, including participatory learning, teacher-as-collaborator, and the production of meaningful artifacts (Gold, 2001; Cavana, 2009). Others espouse the apparent equity of such courses, as such discussions tend to admit multiple perspectives and yield more even levels of contribution (Light, Colbourn \& Light, 1997). Meyer (2003) conveys several time-based advantages of threaded discussions, including increased time-on-task, extra time for reflection, and sufficient opportunities for everyone to contribute to the discussion.

One of the most widely used frameworks for understanding online learning is the Community of Inquiry framework (Rourke \& Kanuka, 2009; Garrison, 1999). At the core of this program of research is the claim that asynchronous learning environments can foster deep and meaningful learning in the presence of adequate cognitive, social, and teaching presence. Social presence refers to the feeling that others are "actually there" in the environment, whereas teaching presence reflects the instructional, facilitative, and organizational roles of the instructor. Cognitive presence is defined as "the extent to which the participants in any particular configuration of a community of inquiry are able to construct meaning through sustained communication".

Evidence that asynchronous courses can actually foster such presences is mixed. Some argue that asynchronous communication affords in-depth and thoughtful discussions (Branon \& Essex, 2001; Tu \& Corry, 2003). However, when characterizing levels of cognitive presence, there is some evidence (Rourke \& Kanuka, 2009) that the vast majority of student postings 
fall in the lowest levels of cognition. To the extent that this is true, it is unlikely that such a course would lead to meaningful learning (Rourke \& Kanuka, 2009).

Studies of teaching presence, on the other hand, are generally more positive. Rovai (2007) expounds on the importance of having an active teacher to form cohesive learning communities, encourage students, and serve as supporter and facilitator. In addition, asynchronous courses naturally permit the teaching role to be spread across individuals in the form of student moderators or student facilitators. In contrast to face-to-face courses, students in asynchronous courses can assume a more central teaching presence role (Heckman \& Annabi, 2005), especially when those students are assigned to moderate weekly discussions (Rourke \& Anderson, 2002). Rourke and Anderson (2002) argue that addressing the constituents of teaching presence can be daunting for a single teacher, and that student moderation may help distribute and balance such responsibilities. Tagg (1994) argued that student moderation sets up a context within which students and teachers can complement one another's strengths. In this study, two students each week signed up for the role of topic leader (submitting the initial contribution) and topic reviewer (submitting a final, synthesis posting); it was found that such student involvement promoted increased cohesion and structure in the discussions. Furthermore, interaction and participation was increased by virtue of having students publicly commit to their moderator roles.

Social presence has been linked to several desirable aspects of student perception and learning in online courses. For example, high levels of social presence can lead to students' perceptions of increased learning, course satisfaction, and emotional satisfaction (Nippard \& Murphy, 2008). Social presence fosters critical thinking and makes interaction intrinsically rewarding (Rourke, Anderson, Garrison \& Archer, 2001), and may be necessary for effective online instruction, the construction and negotiation of knowledge, and the establishment of a community of learners (Rockinson-Szapkiw, 2009). As we discuss in the next subsection, many agree that social presence is more easily fostered in a synchronous environment, where teachers and students can be seen as more immediate, the media is significantly rich to carry social presence indicators, and some elements of face-to-face social presence are restored. 


\subsection{Synchronous Communication}

Synchronous communication involves realtime communication between teachers and students, most commonly in the form of text chat (Johnson, 2006). Several studies suggest that social presence is higher in synchronous chat than in asynchronous discussion. For example, Schwier and Balbar (2002) discuss and compare asynchronous discussion to synchronous chat in a graduate education course. The enrolled students were professionals with families, living quite far from campus. Rather than have students come to campus more frequently, they held monthly "marathon" sessions on weekends. Among other concerns, the instructor felt that such monthly meetings did not promote the required level of interpersonal engagement, and instituted a weekly synchronous chat as a possible remedy. The purpose of the chats was to give students more opportunities to discuss course content. The authors identify several benefits of these synchronous chats that are related to social presence. Synchronous chat contributed to the "continuity and convenience" of the class, helped sustain regular contact, and created a sense of urgency and immediacy. Discussions were often passionate, extending to email discussions following the scheduled chat sessions. To account for subtleties lost in hastily-composed prose, participants began using others' names as well as emoticons.

One of the main hypotheses of Kuyath (2008) was that students would perceive more social presence in synchronous chat than in asynchronous media such as email. To test this, the author created two groups (equivalent on age, gender, ethnicity and GPA), and subjected them to a switching replications, non-equivalent group design (NEGD) study. This arrangement gives all participants the opportunity to receive the synchronous chat treatment and is therefore academically fair. All students began with a pre-test, then group 1 received the treatment, and all students received a post-test. Then, the groups were switched: group 2 received the treatment (and group 1 went back to using only email), and all students took a final post-test. The pre-test and both post-tests were preceded by having students work on an assignment where they asked the instructor questions using the allowed mode. The pretest and post-tests involved Likert surveys as well as the submission of the assignment completed prior. At the time of the pre-test, all students had communicated with the instructor using only email. Social presence was measured using a five-point Likert scale. Looking at the results obtained at the first post-test, students who used chat felt significantly more social presence than those students using email. Similar results were obtained on 
the second post-test, where the mode used by group 1 and group 2 to ask questions had been switched.

Rockinson-Szapkiw (2009) compared cognitive presence, social presence, teaching presence, and perceived learning among students who used only asynchronous communication to students that used a combination of asynchronous and synchronous tools. The study focuses on students studying in the "helping professions" (e.g. counselling, psychology), since online offerings and hence research about those offerings is currently sparse. Two experiments were conducted: a "causal comparative design" (i.e. a post-test only design) and a "true experimental design". For the former, convenience sampling through lists of accredited institutions was used, and the initial respondents recruited further participants (snowball sampling). In the latter, one undergraduate and one graduate course were convenience-sampled. In all combined synchronous and asynchronous courses, audio was used by students - sometimes also with their instructors - to discuss and collaborate; chat was also frequently used. Among other instruments, students completed the Community of Inquiry Framework Survey. The comparative experiment found that social presence was higher for students who used a combination of both modes compared to only the asynchronous mode, though the effect size was small. The true experiment found no such significant difference, though mean social presence scores were higher for students in the combined courses than for students in the asynchronous courses. Even though statistical data is inconclusive, qualitative survey data support the assertion that students are positive about the capacity of synchronous communication to increase interaction and collaboration, and to address concerns such as isolation that present themselves in asynchronous communication. Further, students frequently indicate that the media itself (e.g. synchronous audio or chat) was significant for promoting social presence and social interaction.

Hrastinski (2006) compared two offerings of a business communications course: one that included only asynchronous communication, and one that additionally included synchronous chat. Analyzing synchronous chat, the author found two nonoverlapping types of students: adopters (those that frequently used the chat) and non-adopters. In the combined offering, students felt less connected to the class, though the subset of students that were chat adopters felt a strong sense of community. This study, however, used perceptual data obtained by surveying students, and it is not clear to what extent this data accurately reflected what objectively took place in the discussion environments. 
It seems reasonable to conclude that synchronous communication has positive impacts on the level of social presence, at least for those students who use it. However, is this at the expense of course content and learning, or can synchronous communication be used to discuss deep course issues at least as effectively as would be the case in asynchronous discussion? That is, can synchronous communication foster cognitive presence in addition to social presence?

Schwier and Balbar (2002) suggest that synchronous communication works well for content that "inspires natural debate or passion", but that asynchronous communication may be preferred for content that is dry or requires reflection. Synchronous communication may not provide the time or concentration required to engage deep ideas. Nippard and Murphy (2008) concur: "[e]xpressions of social presence by the students and teachers occurred most often in a context of digressions that drew attention away from the delivery of content".

Johnson (2008) analyzed learning gains in an educational psychology course where students used synchronous chat or asynchronous discussion to discuss four different case studies. Students were divided into two groups: discussion-chat-discussion-chat, and chat-discussion-chat-discussion. This ensured that all students used both methods equally throughout the course. Each case study was followed by a three-question multiple-choice exam; students were additionally asked which of the two modes most helped their learning. There were no significant differences in student learning across the two modes, a surprising finding in light of the studies cited above (Schwier \& Balbar, 2002; Nippard \& Murphy, 2008). That is, we have some evidence that synchronous chat can sufficiently support cognitive activity in addition to social activity.

Further evidence that synchronous chat can be useful for content learning can be found in the study by Kuyath (2008). In addition to comparing social presence of chat and synchronous discussion, Kuyath compared the two modes on content learning. Since a Likert scale would not be appropriate for measuring academic performance, Kuyath used grades earned on an assignment where students could use email or chat to ask questions of their instructor. Kuyath found that chat students performed significantly better on the assignments than email students. Similarly, Stein, Wanstreet, Glazer, Engle, Harris, Johnston, Simons \& Trinko (2007) argue that, with the appropriate teaching and social presence, students can arrive at shared understanding in a synchronous environment. Their study shows that early chat 
sessions contained fewer instances of cognitive presence than later sessions. Chat sessions tended to begin with indicators of social presence and teaching presence, serving to acquaint students and focus them on their shared goals. Therefore, it seems that sufficient time and community-building must occur prior to students using synchronous settings for high-level thinking.

Overall, then, some researchers suggest that asynchronous discussion is to be preferred for reflection and higher-order processing, whereas others do not discount the possible contributions of synchronous chat to cognitive presence and perceived learning (Rockinson-Szapkiw, 2009). Each mode, with appropriate facilitation, can support different forms of critical thinking and, for this reason, the use of both modes is of great interest to researchers.

Most relevant studies in this area do not consider the combined effects of both modes in the same learning environment. For example, some studies compare courses or discussions using synchronous tools to those using asynchronous tools (Dudding \& Drulia, 2009; Davidson-Shivers, Muilenburg \& Tanner, 2001); others compare single-mode courses to courses using at least two modes (Rockinson-Szapkiw, 2009; Hrastinski, 2006). In these latter studies, the focus is not on the independent contributions of each mode, but on the improvement obtained when adding synchronous tools to asynchronous courses or face-to-face courses (Cox, Carr \& Hall, 2004). Hines and Pearl (2004) expound on the requirements for productive synchronous communication, while acknowledging that asynchronous communication is also important. Others present compelling case studies or arguments for the importance of synchronous communication (Blankson \& Kyei-Blankson, 2008; Dickey, 2003; Shotsberger, 2000). Finally, recent work seeks to address recurrent problems with synchronous communication, such as the confusion caused by not being able to explicitly see links between messages (Holmer, Lukosch \& Kunz, 2009) or the technology required to support the use of synchronous moderators (Schwarz \& Asterhan, 2011).

Some existing studies do suggest the combined benefits of both modes, generally with encouraging results. For example, Ligorio (2001) studied the use of synchronous chat and asynchronous discussion in a multi-school online collaboration. They found that students' interactive use of both modes increased over time, and that each mode served a distinct and complementary purpose. The asynchronous mode was often used to hold discussions relating to shared collaborations, the results of which would later be used to inform future synchronous activities. The present study is designed to add to what we know about the simultaneous offering to students of both modes. 


\section{Methods}

\subsection{Study Context}

In order to investigate the relationship between asynchronous and synchronous usage, we selected nine graduate education courses offered at a large Canadian research university. These courses were selected because they met the following criteria. First, the courses were all fully-online courses, not hybrid or blended courses with a face-to-face component. We excluded such courses because we felt that a face-to-face component would interact with the type of discourse expressed in the asynchronous and synchronous tools. Because we are aggregating students across courses, it is desirable that all students have access to the same tools and communication modalities. Second, all of the courses we chose made use of synchronous and asynchronous tools. These courses all took place in an online learning environment developed at our institution, whose features we briefly describe.

When students log-in to the environment, they are presented with a list of other students currently online. Students can click on others' names in order to send private messages. A single private message may be sent to one or more individuals at the same time. When such messages are sent, the recipients, if online, are immediately notified of the new message, and may then respond to the sender. In this way, students can engage in synchronous chat-like sessions. Note that, like other chat services, recipients who have gone offline will receive intervening private messages the next time they access the course.

In terms of asynchronous communication, our environment provides a discussion forum similar to that of other learning environments such as Blackboard. Typically, the instructor creates one forum for each week of the course, and it is within these forums that the discussions take place. Students are able to read existing notes, reply to those notes, or create new notes. When students reply to others, threaded structures are created and visually displayed as trees of notes. In the courses we analyzed, active asynchronous communication was required for part of the course grade (typically 10\%).

In total, the nine courses we analyzed contained 222 students; each course took place in the 2010-2011 academic year. Table 1 contains more information on each course. In what follows, we use the term note to refer to an asynchronous posting, and message to refer to a message sent synchronously. 
Table 1: Courses used in the study.

\begin{tabular}{l|l} 
Name & No. \\
Second Language Learning & 17 \\
School Science and the Search & 9 \\
for Optimum Living Conditions & \\
Applications of CMC & 18 \\
Rethinking Skills & 13 \\
Assessment for Instruction & 25 \\
Interpreting Education Research & 39 \\
Computers in Education & 22 \\
Learning Disabilities & 30 \\
Organizational Theory & 49
\end{tabular}

\subsection{Research Questions}

Much of the early work on asynchronous communication used quantitative techniques to characterize writing patterns or communication structures (Guzdial, 1997; Hewitt \& Teplovs, 1999). These studies relied on large numbers of students in many courses in order to quantify broad trends across contexts. While more contemporary work argues that quantitative analysis in asynchronous communication has run its course (Schrire, 2006), such quantitative analysis initially proved fruitful in generating hypotheses that are now being explored qualitatively. As just one example of this quantitativequalitative pairing, Hewitt and Teplovs (1999) found that threads in asynchronous discussions often do not last very long, contrary to predictions that such communication should allow for deep, extended discussions. Later, Hewitt (2005) followed up with qualitative analysis in the form of student interviews in order to understand exactly why the earlier quantitative patterns were seen.

The relative infancy of synchronous communication research led us to quantitatively explore two research questions, as follows.

- How do the patterns of discourse differ between synchronous messages and asynchronous notes? This question arose from the above-cited research suggesting that synchronous chat is more social and immediate than asynchronous notes. Specifically, we are interested in cognitive/academic and social process differences in usage between modes, in order to further our understanding of the ways that each mode supports 
facets of social and cognitive presence.

- How do frequent and infrequent chat participants differ in terms of their asynchronous note-production and note-reading behaviors?

Since asynchronous communication is the means by which course instructors expect dialog negotiation, we hypothesized that synchronous chat would be used for more personal, less academically relevant matters. Therefore, to investigate our first research question, we use several metrics that we feel differentiate social talk from academic talk. First, we use the Academic Word List (AWL) (Coxhead, 2000), a collection of the most frequentlyoccurring words in academic texts that do not occur frequently in other types of texts. We hypothesized that such words would occur more frequently in asynchronous notes. Second, we used Flesch reading ease score, which is a measure of the ease with which text can be read. Text with long sentences containing long, multi-syllable words is deemed more difficult to read than text containing shorter sentences made up of shorter words. Low Flesch reading ease scores correspond to text that is more difficult to read compared to text with higher Flesch reading ease scores. Previous literature suggests that the reading ease metric is useful for determining broad communication trends of online transcripts. For example, Hewitt and Peters (2007) found that courses with high reading ease were more interactive than courses with low reading ease. Here, we hypothesized that private messages would be easier to read than asynchronous notes, and hence that private messages would have higher Flesch reading ease scores.

To more directly measure social and cognitive processes, we also performed analysis with the LIWC software (Pennebaker, Chung, Ireland, Gonzales \& Booth, 2007). This software contains dictionaries for many linguisticbased categories, and tabulates words belonging to each dictionary when analyzing texts. It has been used in past examinations into the relationship between emotions expressed in online discussions and grades on term projects (Yoo \& Kim, 2012). Here, we are particularly interested in three LIWC dictionaries: social processes, affective processes, and cognitive processes. The first category contains words such as "talk", "child", and other words relating to social experiences and human interaction. The second captures positive and negative emotions, whose importance stems from its centrality to the definition of social presence (Rourke et al., 2001). The third contains words such as "think", "consider", "cause", and other words relating to cognitive mechanics. 
As a final metric, we have included word count, since it has been used in past research as a manifest indicator of sustained interaction (Schrire, 2006).

Meyer (2003) described how time expands in online courses, in the sense that the course is always available and that there is always work that can be done. While some students enjoyed the increased availability for timeon-task, others felt overwhelmed by the constant availability of the course. We therefore wondered how adding a new mode of communication would impact the amount of time and effort invested in the course. Would students who frequently use synchronous communication ease off on the asynchronous communication? Or, alternately, would synchronous chat further expand the time-on-task for these students, as reflected in a corresponding increase in asynchronous activity? To address the second of our research questions, we examined relationships between message production and the following notereading and note-writing behaviors: number of notes written, average word count of notes, number of notes read, and note scan rate.

Our online environment counts a note as read as soon as it is opened, regardless of the length of time that the note is viewed. Therefore, simply comparing mean numbers of notes cannot differentiate students who open many notes but do not read them from students who open comparable numbers of notes and read them carefully. To obtain a more fine-grained measure of student reading practices, we use the scan rate metric (Hewitt, Brett \& Peters, 2007). A student is said to scan a note when they read that note at eight words-per-second or more, and the scan rate is the percentage of notes opened by a student that were scanned. Since reading at or above eight words-per-second is indicative of skimming (Hewitt et al., 2007), the scan rate captures the percentage of notes that were opened but that were likely skimmed or only partially read. For example, if a student opens 20 notes, and reads 15 of those at a rate faster than 8 words-per-second, their scan rate would be 75 percent; that is, of the notes opened by the student, 75 percent were read extremely quickly. To be sure, scan rate provides only a lower bound estimate on the percentage of notes that were opened and closed too quickly to have been read thoroughly. For example, a student might open a short note for several minutes (indicative of a thorough reading), but nevertheless not read the note at all (e.g. they switched to another application on their computer). That is, scan rate may "miss" some scans, but accurately captures all true scans. 


\section{Results}

Before carrying out data analysis, we set $\alpha=.05$. Table 2 and Table 3 summarize the analyses.

For the analyses in Table 2, we included only students who wrote at least one synchronous message. We did this so as to avoid using arbitrary values (such as 0 ) for students that did not write any synchronous messages. Therefore, these analyses were based on 190 of the 222 total students.

In terms of word count, we found that synchronous messages were significantly shorter (31.8 words on average) than asynchronous notes (160.91 words on average). A paired t-test confirms that this result is highly significant $(t(189)=22.78, p=0)$.

To compare asynchronous notes and synchronous messages on reading ease, we calculated each student's average reading ease in each mode. We then carried out a paired t-test to determine whether reading ease differed across the modes. We found that messages were significantly easier to read than asynchronous notes (a reading ease score of 79.39 compared to 55.69; $t(189)=27.30, p=0)$. To determine whether AWL usage differed between asynchronous notes and synchronous messages, we calculated two scores for each student: the average percentage of AWL words used in private messages and the average percentage of AWL words used in asynchronous notes. Again, we used a paired t-test to determine whether there was a significant mode difference. We found that asynchronous notes contained much more use of AWL words (7.5 percent compared to 3.9 percent; $t(189)=19.99$, $p=0)$.

These findings are reinforced by the LIWC analyses. Using the social dictionary, we found that messages contained a larger proportion of social words than did notes (12.02 percent compared to 8.21 percent; $t(189)=9.61, p=$ $0)$. Similarly, compared to notes, messages contained more emotional words (6.79 percent compared to 4.51 percent; $t(189)=3.43 ; p=.0008)$. By contrast, when using the dictionary of cognitive words, we found that notes contained a larger percentage of words indicating cognitive processing than messages (18.95 percent compared to 16.17 percent; $t(189)=7.52, p=0)$.

To examine the relationship between synchronous and asynchronous communication, we computed correlations between number of synchronous messages written and various asynchronous reading/writing measures (see Table 3). For these analyses, we used all 222 students in our data set. The average number of messages written by these students, including students 
Table 2: Comparisons of Synchronous and Asynchronous Communication features.

\begin{tabular}{l|l|l|l|l|l} 
& Sync Mean & Async Mean & $\mathbf{t}$ & $\mathbf{d f}$ & $\mathbf{p}$ \\
Word Count & 31.08 & 160.91 & 22.78 & 189 & 0 \\
Reading Ease & 79.39 & 55.69 & 27.30 & 189 & 0 \\
AWL Percentage & 3.9 & 7.5 & 19.99 & 189 & 0 \\
Social Percentage & 12.02 & 8.21 & 9.61 & 189 & 0 \\
Emotional Percentage & 6.79 & 4.51 & 3.43 & 189 & .0008 \\
Cognitive Percentage & 16.17 & 18.95 & 7.52 & 189 & 0
\end{tabular}

Table 3: Correlation between messages written and various asynchronous measures.

\begin{tabular}{l|l|l|l|l|} 
& Mean & $\mathbf{r}$ msgs written & $\mathbf{d f}$ & $\mathbf{p}$ \\
Notes Written & 52.42 & .60 & 220 & 0 \\
Note Length & 166.39 words & -.08 & 220 & .24 \\
Notes Read & 704.43 & .36 & 220 & 0 \\
Note Scan Rate & $36.1 \%$ & -.18 & 220 & .007 \\
Time Online & 39.31 hours & .61 & 220 & 0
\end{tabular}

who did not write any such messages, was 14.03. First, as indicated by the first two data rows of Table 3, we found a highly significant positive correlation between number of messages written and number of notes written $(r=0.6, p=0)$, but no significant correlation $(p=0.21)$ between number of messages written and average length of notes. Taken together, we find that students who are active in the synchronous mode send more notes (of comparable size) than those less active in the synchronous mode.

Second, we found a moderate positive correlation between number of messages written and number of notes read $(r=0.36, p=0)$, suggesting that active synchronous students not only write more asynchronous notes, but also read more asynchronous notes than their peers. As described above, however, opening a note does not indicate whether the note was likely to have been read at a rate indicative of scan-reading. In considering scan rate, we find a significant negative correlation between number of messages written and scan rate while reading other students' notes $(r=-0.18, p=0.007)$. That is, students who write more synchronous messages engage in less scanning behavior than other students. Of course, we cannot equate less scanning with more engaged or careful reading practices, only that less scanning makes it more likely that the opened notes are being carefully read.

These relationships between synchronous messages on one hand and asyn- 
chronous reading and writing practices on the other suggest that highly-active synchronous students may spend more time in the environment overall than their peers. Indeed, this too is borne from the data: we find a significant positive relationship between number of messages sent and time spent online $(r=0.61, p=0)$. As further discussed in the next section, students more active in the synchronous mode were more active in the asynchronous mode and therefore necessarily more active overall.

\section{Discussion}

What happens when students are given the opportunity to use two modes in a single online course? There are two defendable hypotheses. First, students might not spend any additional time in the course: they would distribute that fixed time in proportions according to personal preference and work styles. Second, the added mode might not take focus from the other mode, but may instead serve complementary roles. This study lends support to the second hypothesis. To be sure, our study is not an experiment that allows us to contrast single-mode courses against dual-mode courses. We do not know whether these same students would spend more or less time in an otherwise similar course that lacked synchronous communication. However, we did find that the most active synchronous students were also the most active asynchronous students. For these students, at least, it appears that they were not forced to make a mode-choice: instead, they actively used both modes, and spent significantly more time online in order to do so.

If we assume that synchronous communication increases time spent in our courses, we must be careful not to make value judgments on this result in isolation. Indeed, as already noted, time expansion in online courses is a serious problem for some students (Meyer, 2003). However, since activity in one mode is associated with activity in the other, what we can argue is that the combined effects of these modes may better address the alleged prerequisites for online learning. Above, we invoked the community of inquiry framework to organize our literature review. There, we argued that sustaining the three presences - social, teaching, and cognitive - is unlikely to occur using a single mode, if for no other reason than the seeming inability of asynchronous discussion to measure up to synchronous chat on levels of social presence. If students are willing to engage in both modes, we argue that this affords increased opportunity for meaningful learning to occur. Of course, as online educators, we cannot assume that simply adding a new mode of 
communication will increase interaction. Such an argument reflects a powerful myth of online learning: that increased connectivity deterministically leads to increased interaction (Sarker \& Nicholson, 2005). Yet, synchronous communication seems to set up a context within which interaction is likely to increase. In addition, we hypothesize that the specific function of each mode is different and complementary. Our results showed that private messages were easier to read and used less academic and cognitively-related terminology than asynchronous notes. In addition, asynchronous notes were longer, possibly indicating more thought-out and thorough responses. Therefore, synchronous communication may indeed serve to fill a social gap that may exist under asynchronous communication alone.

What is required next is an in-depth, qualitative analysis of students reactions to and use of private messages. Indeed, examining interaction analysis techniques that have been developed for the analysis of computer conferences, Gunawardena, Lowe \& Anderson (1997) argued that the educational importance or quality of interactions in a CMC environment requires content analysis of transcripts. Gunawardena et al. (1997) analyzed transcripts of 554 participants and developed a model using grounded theory principles. According to this model, meanings are negotiated and knowledge is co-constructed through five progressive phases, each of which was discovered through close association with the data. Such inductive descriptions of meaning-making are particularly alluring for the case of synchronous communication, where significantly less is known. We invite and encourage researchers to pursue such rigorous analysis of synchronous transcripts.

In our sample of courses, teachers expressed varying motivations for using private messages. Some teachers made students aware of the medium by sending personalized messages to each student at the start of the course. Other instructors encouraged students to use the available tools in order to coordinate group activities or to organize meetings and strategies for collaboration. Yet, we do not have an account of the students' motivations that caused engagement with the medium. In particular, interview and survey data would allow us to further examine our hypothesis that both modes are complementary in addressing prerequisites for effective online learning.

As a final note, it is important to add that instant-messaging applications are extremely popular with today's students, and that the lack of synchronous tools in an online course therefore does not mean students are not communicating synchronously. Indeed, if such tools are unavailable directly in their course environment, students may seek synchronous communication 
with peers through other external means. Interviews would allow us to determine just how frequently this practice occurs, and further understand the relative benefits and cautions involved in providing students a workable synchronous mechanism within the course itself.

\section{Conclusion}

While this is a single study investigating a fairly new question in the online learning literature, the results indicate that introducing an additional private messaging function into the asynchronous course environment can have positive effects. The strong correlation between private messages written and asynchronous notes written suggests that there are many engaged students who are taking advantage of the affordances of private messages in order to participate in new ways. This is an important finding: one could imagine a new means of communication within the course environment "distracting" students away from the public, shared space. Our results suggest that this fragmenting and privatizing does not seem to occur. A signifi-

cant relationship between the number of private messages and the number of asynchronous notes might also suggest that the personal nature of messaging increases the sense of community among class participants and encourages more interactivity. We find that synchronous messages and asynchronous notes differ in terms of reading ease, academic content and social processes, suggesting that both may fill complementary and overlapping roles in the evolving discourse.

Authors' Note. The first two authors contributed equally to this manuscript.

\section{References}

Blankson, J., \& Kyei-Blankson, L. (2008). Nontraditional students' perception of a blended course: Integrating synchronous online discussion and face-to-face instruction. Journal of Interactive Learning Research, 19, 421-438.

Branon, R. F., \& Essex, C. (2001). Synchronous and asynchronous communication tools in distance education: A survey of instructors. TechTrends, $45,36-42$.

Brown, J. S., Collins, A., \& Duguid, P. (1989). Situated cognition and the culture of learning. Educational Researcher, 18, 32-42. 
Cavana, M. (2009). Closing the circle: From dewey to web 2.0. In c. Payne (Ed.), Information Technology and Constructivism in Higher Education: Progressive Learning Frameworks (pp. 1-13). Hershey, PA: Igi Global.

Chen, Y., Liu, C., \& Wong, R. (2007). The adoption of synchronous and asynchronous media in the teaching of a second language. Issues in Information Systems, 3, 217-223.

Cox, G., Carr, T., \& Hall, M. (2004). Evaluating the use of synchronous communication in two blended courses. Journal of Computer Assisted Learning, 20, 183-193.

Coxhead, A. (2000). A new academic word list. TESOL Quarterly, 34, 213-238.

Davidson-Shivers, G. V., Muilenburg, L. Y., \& Tanner, E. J. (2001). How do students participate in synchronous and asynchronous online discussions? Journal of Educational Computing Research, 25, 351-366.

Dewey, J. (1963). Experience and education. New York: Macmillan.

Dickey, M. D. (2003). Teaching in 3d: Pedagogical affordances and constraints of $3 \mathrm{~d}$ virtual worlds for synchronous distance learning. Distance Education, 24, 105-121.

Dudding, C., \& Drulia, T. (2009). Analysis of synchronous and asynchronous discussion forums: A pilot study. In G. Siemens, \& C. Fulford (Eds.), Proceedings of World Conference on Educational Multimedia, Hypermedia and Telecommunications 2009 (pp. 631-634). Chesapeake, VA: AACE.

Fung, Y. H. (2004). Collaborative online learning: interaction patterns and limiting factors. Open Learning, 19, 54-72.

Garrison, D. (1999). Critical inquiry in a text-based environment: Computer conferencing in higher education. The Internet and Higher Education, 2, $87-105$.

Gold, S. (2001). A constructivist approach to online training for online teachers. Journal of Asynchronous Learning Networks, 5, 35-57. 
Gunawardena, C., Lowe, C., \& Anderson, T. (1997). Analysis of a global online debate and the development of an interaction analysis model for examining social construction of knowledge in computer conferencing. Journal of Educational Computing Research, 17, 395-429.

Guzdial, M. (1997). Information ecology of collaborations in educational settings: Influence of a tool. In Proceedings of the 1997 conference on Computer support for collaborative learning CSCL'97 (pp. 83-90). Toronto, $\mathrm{ON}$ : International Society of the Learning Sciences.

Heckman, R., \& Annabi, H. (2005). A content analytic comparison of learning processes in online and face-to-face case study discussions. Journal of Computer-Mediated Communication, 10.

Henning, W. (2004). Everyday cognition and situated learning. In D. Jonassen (Ed.), Handbook of research on educational communications and technology (2nd ed.) (pp. 143-168). Mahwah, NJ: Erlbaum.

Hewitt, J. (2005). Toward an understanding of how threads die in asynchronous computer conferences. Journal of the Learning Sciences, 14, $567-589$.

Hewitt, J., Brett, C., \& Peters, V. L. (2007). Scan rate: A new metric for the analysis of reading behaviors in asynchronous computer conferencing environments. American Journal of Distance Education, 21, 215-231.

Hewitt, J., \& Peters, V. (2007). The relationship between student interaction and message readability in asynchronous online discussions. In Proceedings of the 2007 international conference on Computer supported collaborative learning CSCL'07 (pp. 292-294). New Brunswick, NJ: International Society of the Learning Sciences.

Hewitt, J., \& Teplovs, C. (1999). An analysis of growth patterns in computer conferencing threads. In Proceedings of the 1999 conference on Computer support for collaborative learning CSCL '99 (pp. 232-241). Palo Alto, CA: International Society of the Learning Sciences.

Hill, J., Song, L., \& West, R. (2009). Social learning theory and web-based learning environments: A review of research and discussion of implications. The American Journal of Distance Education, 23, 88-103. 
Hines, R. A., \& Pearl, C. E. (2004). Increasing interaction in web-based instruction: Using synchronous chats and asynchronous discussions. Rural Special Education Quarterly, 23, 33-36.

Holmer, T., Lukosch, S., \& Kunz, V. (2009). Diminishing chat confusion by multiple visualizations. Journal of Universal Computer Science, 15, 3139-3157.

Hrastinski, S. (2006). Introducing an informal synchronous medium in a distance learning course: How is participation affected? Internet and Higher Education, 9, 117-131.

Johnson, G. (2006). Synchronous and asynchronous text-based cmc in educational contexts: A review of recent research. TechTrends, 50, 46-53.

Johnson, G. (2008). The relative learning benefits of synchronous and asynchronous text-based discussion. British Journal of Educational Technology, 39, 166-169.

Johnson, S., \& Aragon, S. (2003). An instructional strategy framework for online learning environments. New Directions for Adult and Continuing Education, 2003, 31-43.

Kuyath, S. (2008). The Social Presence Of Instant Messaging: Effects On Student Satisfaction, Perceived Learning, And Performance In Distance Education. Ph.D. thesis University of North Carolina at Charlotte.

Light, P., Colbourn, C., \& Light, V. (1997). Computer-mediated tutorial support for conventional university courses. Journal of Computer Assisted Learning, 13, 228-235.

Ligorio, M. B. (2001). Integrating communication formats: Synchronous versus asynchronous and text-based versus visual. Computers $\&$ Education, $37,103-125$.

Meyer, K. A. (2003). Face-to-face versus threaded discussions: The role of time and higher-order thinking. Journal of Asynchronous Learning Networks, 7, 55-65.

Morse, K. (2003). Does one size fit all? exploring asynchronous learning in a multicultural environment. Journal of Asynchronous Learning Networks, 7, $37-55$. 
Nippard, E., \& Murphy, E. (2008). Social presence in the web-based synchronous secondary classroom. Canadian Journal of Learning and Technology / La revue canadienne de lapprentissage et de la technologie, 33.

Pennebaker, J., Chung, C., Ireland, M., Gonzales, A., \& Booth, R. (2007). The development and psychometric properties of liwc2007. http://www.liwc.net/howliwcworks.php.

Rockinson-Szapkiw, A. (2009). The Impact Of Asynchronous And Synchronous Instruction And Discussion On Cognitive Presence, Social Presence, Teaching Presence, And Learning. Ph.D. thesis Regent University.

Rourke, L., \& Anderson, T. (2002). Using peer teams to lead online discussions. Journal Of Interactive Media In Education, 2002.

Rourke, L., Anderson, T., Garrison, D. R., \& Archer, W. (2001). Assessing social presence in asynchronous, text-based computer conferencing. Journal of Distance Education, 14, 51-70.

Rourke, L., \& Kanuka, H. (2009). Learning in communities of inquiry: A review of the literature. Journal of Distance Education, 23, 19-48.

Rovai, A. (2007). Facilitating online discussions effectively. The Internet and Higher Education, 10, 77-88.

Sarker, S., \& Nicholson, J. (2005). Exploring the myths about online education in information systems. Informing Science Journal, 8, 58-73.

Schrire, S. (2006). Knowledge building in asynchronous discussion groups: going beyond quantitative analysis. Computers \& Education, 46, 49-70.

Schwarz, B. B., \& Asterhan, C. S. (2011). E-moderation of synchronous discussions in educational settings: A nascent practice. Journal of the Learning Sciences, 20, 395-442.

Schwier, R. A., \& Balbar, S. (2002). The interplay of content and community in synchronous and asynchronous communication: Virtual communication in a graduate seminar. Canadian Journal of Learning and Technology / La revue canadienne de lapprentissage et de la technologie, 28.

Shotsberger, P. G. (2000). The human touch: Synchronous communication in web-based learning. Educational Technology, 40, 53-56. 
Stacey, E. (1999). Collaborative learning in an online environment. Journal of Distance Education, 14, 14-33.

Stein, D., Wanstreet, C., Glazer, H., Engle, C., Harris, R., Johnston, S., Simons, M., \& Trinko, L. (2007). Creating shared understanding through chats in a community of inquiry. The Internet and Higher Education, 10, 103-115.

Swan, K. (2005). A constructivist model for thinking about learning online. In J. Bourne, \& J. Moore (Eds.), Elements of Quality Online Education: Engaging Communities (pp. 13-30). Needham, MA: Sloan-C.

Tagg, A. C. (1994). Leadership from within: Student moderation of computer conferences. American Journal of Distance Education, 8, 40-50.

Tu, C. H., \& Corry, M. (2003). Designs, management tactics, and strategies in asynchronous learning discussions. The Quarterly Review of Distance Education, 4, 303-315.

Vygotsky, L. S. (1978). Mind in society: The development of higher psychological processes. Cambridge, MA: Harvard University Press.

Yoo, J., \& Kim, J. (2012). Predicting learner's project performance with dialogue features in online q\&a discussions. In S. Cerri, W. Clancey, G. Papadourakis, \& K. Panourgia (Eds.), Intelligent Tutoring Systems (pp. 570-575). Springer Berlin / Heidelberg volume 7315 of Lecture Notes in Computer Science. 